\title{
Foetal Images on Political Posters: Bodily Intimacy, Public Display and the Mutability of Photographic Meaning
}

\author{
Fiona Loughnane ${ }^{1 *}$
}

Published: March 1, 2022

\begin{abstract}
Prenatal images on anti-abortion campaign posters in the Irish referendum of 2018 were an overwhelming presence in the ambient spaces of Irish towns and cities, and generated a strong public reaction. This article examines this aspect of the visual and material ephemera of the referendum campaign in order to critique the continued use of in utero images within conservative reproductive politics. The article places existing accounts of the uses and abuses of foetal imagery into an Irish context. Referencing feminist critiques of prenatal images, ethnographic studies of ultrasound, Peter Paul Verbeek's discussion of these photographic practices as complex imbrications of the human and technological and paying attention to a striking, oppositional use of a sonogram by the Spanish photographer Laia Abril, this article will interrogate the assumed stability of meaning which motivates the adoption of prenatal images by anti-abortion campaigns.
\end{abstract}

Keywords: Irish referendum, political posters, Laia Abril, anti-abortion propaganda, foetal imaging

\section{FOETAL IMAGES ON POLITICAL POSTERS}

In the Spring of 2018, the ambient streetscapes of Ireland were blanketed by political posters advocating a No or a Yes vote in the upcoming referendum to repeal the 8th Amendment. A Yes vote, in favour of the removal of the 8th Amendment, which asserted the right to life of the 'unborn,' would allow the restrictive laws governing abortion in the Irish State to be liberalised, while a No vote would preserve the existing status quo. The visibility of these referendum posters was not solely due to their volume and extent in public space-a typical phenomenon in the lead up to all Irish elections - but was also because of their vociferous content, expressed through word and image. My focus here is on one particular type of poster from one side of the referendum campaign: the use of foetal and in utero imagery on announcements designed to encourage a No vote. In addition to outlining the use of these visuals within the specific context of the Irish referendum campaign, this paper will highlight the ambivalences of prenatal images. For the anti-abortion campaign, in utero images offered a powerful form of visual information which harnessed the reality effects of photography to produce an 'unborn' personhood. But for many, subjected to the posters as an unavoidable presence in their lived environments, these views of uterine interiors were overwhelming and oppressive. Photographic images are fugitive and mutable, their meanings are rarely fixed through depiction alone but instead rely on supplementary elements such as context, sequencing, and captions. In utero images demonstrate the same itinerancy which characterises most photographic cultures in their travel between heterogenous contexts-from the medical, to the domestic, to the political (Cadava and Nouzeilles, 2013: 17). These varied social and discursive sites inevitably shape complex, sometimes divergent, meanings.

This article will interrogate the assumed stability of meaning which motivates the adoption of prenatal images by conservative reproductive politics. It will place existing accounts concerning the uses and abuses of in utero visuals into an Irish context. After first mapping the deployment of this imagery as anti-abortion propaganda in the Irish referendum, I will then briefly reference feminist critiques of prenatal images, before considering the contradictory practices and meanings attached to obstetric sonography-engaging with ethnographic studies of ultrasound imaging and Peter Paul Verbeek's view of these photographic practices as complex imbrications of the human and technological. Finally, the article will draw attention to a striking oppositional use of a sonogram by the Spanish photographer, Laia Abril. This image was also on display in Dublin in the weeks leading up to the referendum vote, part of the PhotoIreland Festival's exhibition of Abril's internationally celebrated photographic 
project, $A$ History of Misogyny Part 1: On Abortion (PhotoIreland, 2018; www.laiaabril.com)1. Though less publicly visible than the campaign posters, and largely absent from media discussions of the visuals deployed in the Irish referendum, Abril's image effectively subverts the use of pre-natal imagery to serve anti-abortion agendas. The sonogram was just one small part of Abril's gathering of photographs, text, and audio/visual elements to build a polemical yet nuanced pro-choice argument. However, its presence on a Dublin gallery wall in May 2018 presented a charged contrast with the in utero imagery on the posters in the streets.

The poster is a central medium within Irish political campaigns. Unlike other jurisdictions, where political posters are confined to restricted locations, Irish political posters quickly populate any available lampposts or pylons in cities, towns and rural roadsides in the weeks before any vote. By-laws prohibit dangerous practices (such as hanging the posters too low or obscuring traffic lights) and allow fines against political parties if they fail to remove campaign posters in a timely fashion, but these caveats aside, any imminent vote in Ireland is signalled by a mass of posters in public space (Department of Environment, Climate and Communications, 2019). The referendum of 2018 saw a large volume of campaign posters, exacerbated by the long run in time before the vote'; by the fact that the groups involved had the financial means to cover the costs of extensive postering; and perhaps also influenced by the limitations to online advertising about the referendum, enforced by social media platforms such as Google and Facebook, which cut off one significant space within the political 'air' wars (Facebook Ireland, 2018; Waterson, 2018) ${ }^{3}$. Political posters are designed for impact; they are large enough to be seen from a distance and incorporate colourful graphics and photographic elements, most commonly the portraits of candidates and political leaders. A sense of the striking presence of Irish political posters is offered by Mark Duffy's photographic series, Vote No 1. The project began with images of the local and European elections in 2014 and became an awardwinning photo book in 2015. Duffy's close up images highlight not just the visibility of these announcements, but also their material qualities - such as the textured ridges of corriboard and the accidental interventions of cable ties and general weathering - which work against the polished political personas the posters hope to foster. His presentation of these posters offers an askance view, decoupling them from their propagandistic messages and reinforcing the gap between political promises and social reality (Duffy, 2015). But the 2018 referendum campaign required a very different type of poster-instead of producing a distinct visual identity for political personalities, groupings, and parties - these announcements needed to make a moral argument about a charged and contentious social issue.

The two main anti-abortion campaigns, 'Love Both' and 'Save the 8th', had grown from earlier organisations campaigning on the issue in Ireland since the 1980s, such as the Pro-Life Campaign, the Society for the Protection of Unborn Children, and Youth Defence, and had links to the advocacy group for conservative Catholic values, the Iona Institute (Field, 2018: 13-14). Given this background, both groups were experienced, well organised and well-funded; they quickly populated the streets with striking messaging, which made extensive- though not exclusive - use of prenatal imagery to render the abstract concept of the 'unborn' more tangible and visible ${ }^{4}$. The most prominent pro-choice campaign, 'Together for Yes', was also an umbrella group which pooled the resources and experience of the Abortion Rights Campaign (ARC), the Coalition to Repeal the 8th Amendment, and the National Women's Council of Ireland (NWCI) (Field, 2018: 11-13). Together for Yes were later in getting posters up (following a hugely successful public fundraising drive) and their posters were almost entirely textual (McGreevey, 2018). Their decision to omit images was less a reaction against the charged visuality of the No campaign and was instead motivated by a sense that the message of reproductive choice was too complex to be reduced to a single photograph, a complexity also suggested by their first poster's slogan 'Sometimes a Private Matter Needs Public Support' (Curran, 2018). The slogan alluded to the awkward insertion of intimate, private, reproductive histories into the public discourse of a political campaign — a discomfort that the images deployed by the No campaign ignored.

The No campaign clearly felt that foetal images were among the most important visuals they could present to voters. Statements made in the course of the campaign suggested a belief that these images shared the objective

\footnotetext{
1 The exhibition opened in Dublin's Copper House Gallery on May 1, 2018, three weeks before the referendum vote, and ran until May 31. Abril's work was shown alongside that of the young Irish photographer, Sarah Cullen, whose work also engaged with the theme of abortion from a pro-choice perspective.

${ }^{2}$ The referendum was announced by the Irish government on March 28, allowing for two months of campaigning before the vote on May 25.

${ }^{3}$ These bans were instituted by the tech companies themselves and were widely seen as a response to criticisms of online 'foreign interference' prior to the US Presidential election and the UK's 'Brexit' vote in 2016. Facebook announced that it would no longer accept foreign advertisements relating to the Irish referendum on 8 May 2018. The following day, Google banned any advertisements relating to the Irish referendum from all of their platforms. This was the first time that digital advertising had been curbed prior to a vote in Ireland.

${ }^{4}$ See Side (2020: 104-118) for a broader account of the visuals deployed by the anti-abortion campaign in Ireland's 2018 referendum.
} 
Feminist Encounters: A Journal of Critical Studies in Culture and Politics, 6(1), 09

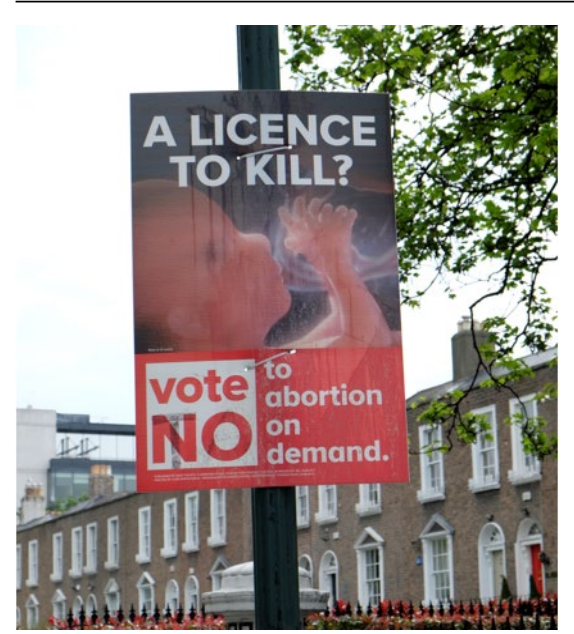

Figure 1. Save the 8th Campaign Poster 'A Licence to Kill? Vote No to Abortion on Demand'. Photograph by Ann Curran, 2018. Used with permission

credibility often assigned to photographs and thus allowed voters to directly see the 'personhood' of the foetus. There was little acknowledgement that in utero images and sonograms are socially mediated images, understood in diverse and contentious ways, dependent on the context in which they are encountered, or the interest and expertise of the viewer (Mitchell, 2001: 7; Roberts, 2012: 4; Taylor, 2008: 19). For example, one 'Save the 8th' press statement argued for the right of the electorate to 'basic information,' suggested that this right could be fulfilled through prenatal scans, and even contended that all television reports on the referendum should include these visuals to ensure a 'fully informed' electorate:

In that context, a fully informed debate need not show graphic images, or upsetting images. But it should show, at a very basic level, what a child in the womb at that age [12 weeks] looks like. Every mother who has had a child in the modern era has seen one of these scans-but most voters have not. The scan shows clearly a developing child, with the identifiable form of a human being, moving and kicking inside the womb (Loughlin, 2018).

In addition to demonstrating the importance attached to prenatal images by the No campaign, this statement also reveals a typical, convenient, semantic slippage between embryo, foetus and child and the use of misleading assertions about foetal development-in the suggestion of deliberate kicking at twelve weeks. The press release is also very revealing of the conservative gender politics at play in the campaign, in its assumption that mothers, but not fathers, would be familiar with ultrasound images.

Katherine Side has traced the strategic changes made to the visual rhetoric of anti-abortion campaigns in Ireland - such as the movement away from religious perspectives and the more central role afforded to womenin an attempt to produce more evolved, persuasive and contemporary messaging. She points out that the persistent use of foetal imagery resists these changes (Side, 2020: 110). Ultrasound scans and in utero images featured prominently in a 2012 billboard campaign produced by Youth Defence using the tagline 'Abortion Tears Her Life Apart,' these adverts generated significant criticism from the Irish public (Morse, 2012). The posters considered below, produced for the 2018 referendum campaign, clearly did not convince voters, given the result. Despite this, the Iona Institute again made use of foetal imagery for their 2019 billboard campaign, 'Still One of Us,' arguing that the soft-focussed and back-lit image of an eleven-week-old foetus made it 'very apparent even at this early stage of pregnancy that we are dealing with a human being.' (Iona Institute, 2019). In all these cases, the use of foetal imagery had greater success in generating strong reactions from the Irish public than in persuading them towards a more conservative position on reproductive rights. Many international anti-abortion campaigns share a similarly strong belief in the ideological power of prenatal imagery - the legislation of certain US states, requiring women to view ultrasound images before accessing abortions, provides a particularly marked example (Guttmacher Institute, 2021). Such legislation assumes that prenatal imagery asserts the improbable personhood of embryos and foetuses so powerfully that it can cancel out the myriad reasons expectant parents decide that a termination of pregnancy is the best choice for them. But the very concept of maternal bonding has become increasingly contentious and the claims that ultrasound enhances this phenomenon are tenuous (Taylor, 2008: 77-115).

Given the longstanding use of foetal images in Irish anti-abortion messaging, the strident tone of Save the 8th's campaign posters for the 2018 referendum is unsurprising. Two of their most widely displayed posters positioned abortion as murder through their combination of in utero images, from later stages of pregnancy, with admonishments such as: 'A License to Kill? Vote No to Abortion on Demand' and 'If Killing an Unborn Baby at Six Months Bothers You, Vote No' (Figure 1 and Figure 2). 


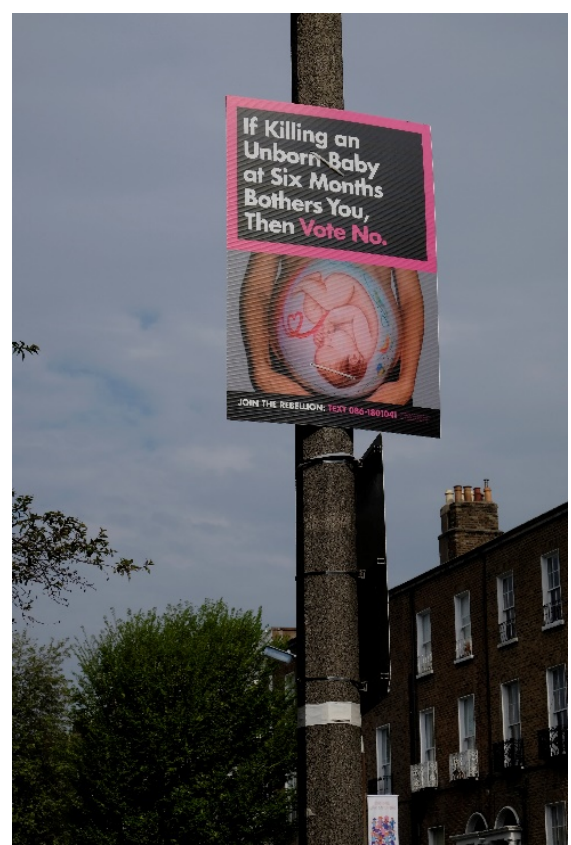

Figure 2. Save the 8th Campaign Poster 'If Killing an Unborn Baby Bothers You Vote No'. Photograph by Ann Curran, 2018. Used with permission

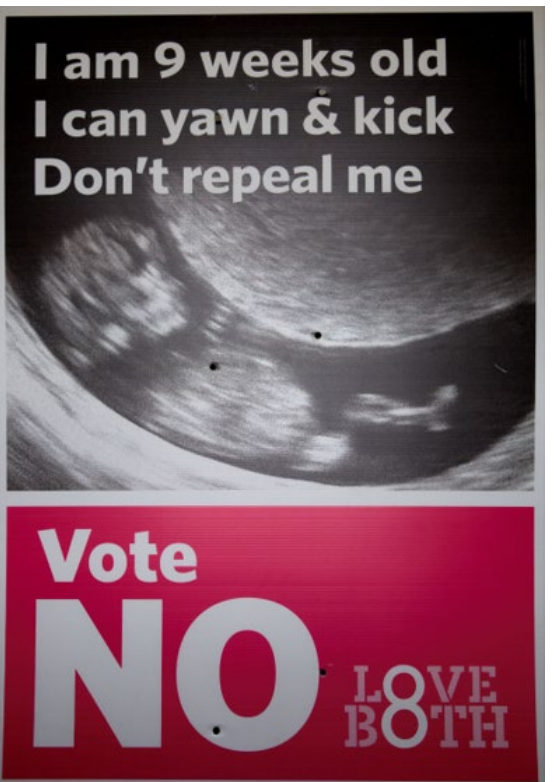

Figure 3. Love Both Campaign Poster 'I Am 9 Weeks Old, I Can Yawn and Kick, Don't Repeal Me'. Photograph by Ann Curran, 2018. Used with permission

'A License to Kill' featured an in utero photograph of the foetus in profile and in close-up, including only the head, with well-defined facial features, and the hands clasped in a gesture that was no doubt meant to be understood as a prayer or a plea. The 'Bothers You' poster involved a very different type of prenatal image; a photograph of a headless pregnant torso, decorated with a body painting of a full-term foetus in pastel colours, exemplified what Lucy Lippard has termed 'unborn bathos' (Lippard, 1995: 249). Save the 8th posters were varied in design, with no consistent colour scheme, typeface, or imagery. The posters produced by the Love Both campaigns had a more unified aesthetic and took a more sentimental approach to the issue. Here too prenatal imagery was carefully selected and presented to emphasise the evolution of recognisably human features. One pictured a grainy 2D sonogram of a nine-week-old embryo, making aesthetic use of the curved wall of the womb, and deploying a scaled-up profile view to emphasise the developing facial features. A second poster used a close up in utero photograph of the face of a foetus apparently sucking its thumb. These visuals were supplemented by a peculiar ventriloquism with first-person assertions of developmental progress: 'I am 9 Weeks Old. I can Yawn and Kick. Don't Repeal Me' and 'My Heart Started Beating at Twenty-Two Days' (Figure 3 and Figure 4). This text was set against blocks of hot pink giving the Love Both announcements a striking cohesiveness. 


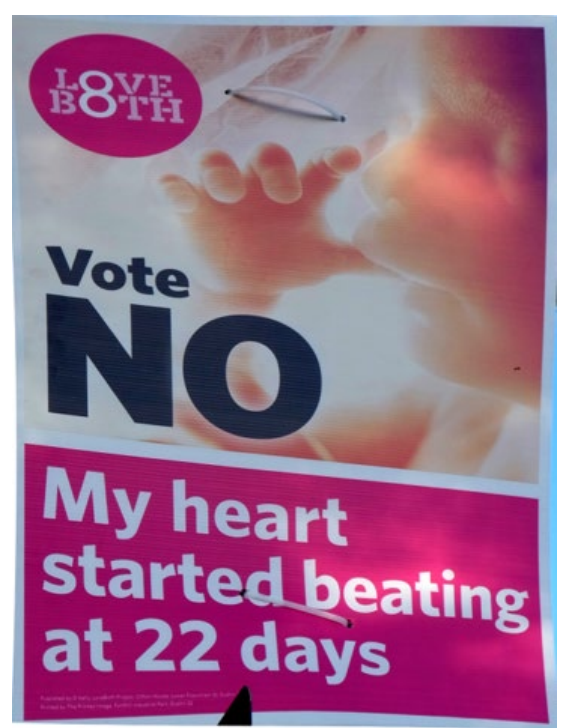

Figure 4. Love Both Campaign Poster 'My Heart Started Beating at 'Twenty-Two Days'. Photograph by Ann Curran, 2018. Used with permission

The use of pink was presumably also intended as a 'feminising' of their message, a chromatic cliché to suggest that they too stood on the side of women, despite their opposition to abortion in even the most difficult of circumstances-including instances of fatal foetal abnormality, serious risks to the health of the mother, or pregnancies resulting from rape.

The Irish announcements followed tropes established by international anti-abortion movements, particularly in North America. Decontextualised images of the foetus construct a free floating and autonomous image of a generalised life before birth, while saccharine captioning supplements the images with an imagined voice, producing a vulnerable 'foetal personhood.' As Lauren Berlant argues, these uses of prenatal images collapse aesthetic and political representation together; foetal personhood is constructed not only through the image but also through a 'strategy of non-diagetic voicing' 'imputing a voice, a consciousness and a self-identity to the fetus that can neither speak its name nor vote' (Berlant, 1994: 151). The insistence of these visuals invokes the indexical nature of photography as a guarantor of truth - a reality effect that is enhanced by their position within the realm of technological and scientific imaging. Bolstered by science, prenatal imagery supposedly offers an objective understanding of the innate humanity of the 'unborn,' and by corollary, the evils of any kind of abortion. But in utero photographs offer a partial view of pregnancy; rather than unmediated, objective records of the development of life within the womb, they are translations which adopt particular perspectives-points of view that remove women from the frame. Rosalind Pollack Petchesky views the reversals of perspective and separations of the visual field, inherent to prenatal imaging, as part of the tendency of all photographs to cut from, reorganise and revision the 'real':

Fetal imagery epitomizes the distortion inherent in all photographic images: their tendency to splice up reality into tiny bits wrenched out of real space and time (Petchesky, 1997: 268).

More directly, photography is implicated in this separation of woman and foetus because the visual phenomenon of intrauterine life is made possible through photographic technologies. These technologies include devices such as micro-lenses and endoscopes, but also a range of medical visualising technologies which are not strictly photographic. Ultrasound is the most notable example of the latter; recorded using sound, rather than light, the resulting sonograms are nonetheless often treated as photographs (Watts, 2007: 232; Wilder and Von Zwehl, 2013).

Lennart Nilsson's photo-essay 'The Drama of Life Before Birth,' published in Life magazine in April 1965, represents the origin moment of a visible, public foetus made possible through photographic practices (Cosgrove, 2013; Jansen, 2019; Stabile, 1992) ${ }^{5}$. The dramatic impact of Nilsson's images is made evident when his photo essay is compared to an earlier story printed in Life, 'The Birth of a Baby' which appeared in the magazine in April 1938. In this earlier narrative photographic images (stills from an instructional film), combine with drawings detailing the growth of the foetus, to offer a chronological account of the different stages of pregnancy through to birth. The

\footnotetext{
${ }^{5}$ Nilsson's photographs were also widely circulated in the pregnancy advice book, A Child is Borm, published in the same year as the Life article, co-authored by Nilsson and several medical professionals. The book sold in vast quantities and numerous iterations and translations were produced, with the most recent edition appearing in 2009 (Jülich, 2015).
} 
story does not offer a female perspective, indeed 'The Birth of a Baby' typifies Life's habitual representation of women through the gaze of male professionals, with 'Dr Wilson' playing a far more significant role than the expectant mother, Mary (Panzer, 2020: 61). But Mary has enough of a presence to be named and the representations of antenatal care, in addition to the still images of labour and birth, offer some account of her bodily experience. In contrast, Nilsson's later photo-essay translated the formerly drawn illustrations of embryonic and foetal development into a disembodied technological spectacle, demonstrating photography's ability to extend human vision in the privileged view it offers of the pregnant interior. More recent medical visualisations of prenatal development by Alexander Tsiaras offer a strikingly similar aesthetic, presenting the biological process as a universal natural wonder; life here unfolds against the cosmos, rather than grows within a woman's body (Stormer, 2008: 649). The scientific authority that attends Nilsson and Tsiaras' images disguises their ambiguities, not least their depiction of life using dead specimens. A few of Nilsson's celebrated images were taken in utero, but most photographs were staged using embryos which had been surgically removed for various reasons. Tsiaras' images were digitally constructed, based in part on MRI scans of specimens from the Carnegie Institute's Department of Embryology (Jansen, 2019; Stabile, 1992: 185; Stormer, 2008: 663-666). Several classic accounts of photography emphasise its memorial functions, the ability of photographs to capture and fix a moment of life in order to stave off death (Metz, 1985; Barthes, 1986; Batchen, 2004). The work of Nilsson and Tsiaras, in contrast, produces an image of 'life' from what Nathan Stormer terms a 'scientific cemetery' (Stormer, 2008: 666).

Feminist discussions of the 'public foetus' have been concerned to critique not just the occlusion of women's bodies, but also the displacement of an intimate, somatic apprehension of pregnancy, in favour of an externalised medico-technical image, with the consequence that a formerly private experience has now been opened up to public inspection and regulation. To offer just a few examples from the vast literature on this topic: Petchesky highlights the ways in which these photographs represent 'the fetus as primary and autonomous, the woman as absent or peripheral' (Petchesky, 1997: 268). She acknowledges that women are not passive in the face of these visual technologies and have themselves generated demand for and welcomed phenomena such as sonograms. Despite this, she concludes:

First, we have to restore women to a central place in the pregnancy scene. To do this, we must create new images that recontextualize the fetus, that place it back into the uterus, and the uterus back into the woman's body, and her body back into its social space (Petchesky, 1997: 287).

Barbara Duden's (1993: 10) more historical approach has drawn attention to the redefinition of pregnant women as 'uterine environments for fetal growth' and the way in which pregnant bodies 'formerly the metaphor for the hidden, the secret and the invisible' have become 'a space for public inspection.'. Finally, Berlant addresses the political implications of this shift; for her, the constructed identity of the public foetus has become so powerful that:

In this context, the pregnant woman becomes the child to the fetus, becoming more minor and less politically represented than the fetus, which is in turn more privileged by law, paternity, and other less institutional family strategies (...) (Berlant, 1994: 147).

More than the bodily experience of pregnancy is diminished here. Foetal images refuse the social and material complexities of human reproduction, they present the 'unborn' outside the social markers of race or class, ignoring how the imposition of reproductive controls has a greater impact on poorer woman, women of colour and transgender pregnant persons; in short, foetal images refuse the messy particularity of actual life, favouring instead ideological abstraction.

Given this wider historical and ideological context, it is unsurprising that the use of prenatal imagery on Irish referendum posters proved contentious and generated anxiety. Writing in The Irish Times, the writer Anne Enright (2018) eloquently identified the discomfort felt by many:

If the argument was over the interior of a woman's body, that interior looked wrong up on a telegraph pole. It seems the feelings we have about foetuses are not neutral and immediate, they are strange and, in any pregnancy, slow to form, so these images did not make us feel, for the most part, protective and warm.

Enright's article offered a rare acknowledgment of the ambiguity of pre-natal images; the realism they produce, she understood, is an uncanny one. Such affective qualities were not the primary focus of most discussions of the referendum posters, instead, Irish public discourse was largely concerned with their misleading content and inappropriate locations. Some of the imagery deployed by groups outside the main anti-abortion campaigns was graphic and clearly unsuitable for general public display. For example, a campaign poster by a group identified only by their website, www.lovethefaith.com, collected by the National Museum of Ireland following the referendum 
vote, followed the shock tactics of North American anti-abortion groups and included a distressing image of dismembered foetal body parts. The mainstream anti-abortion campaigns avoided such visceral imagery, but though their approach was less extreme, the content of their posters was considered both manipulative and deceptive by many public commentators. The announcements suggested a reductive binary of abortion or birth, with no acknowledgment of the other possible outcomes of any pregnancy, such as miscarriage. The Love Both poster 'I am 9 Weeks Old, I can Yawn and Kick, Don't Repeal Me,' featuring a blurred sonogram image, was deemed 'not factually accurate' by the former master of the Coombe maternity hospital in Dublin, Chris Fitzpatrick, in an article written for The Irish Times he pointed to the distress the anti-abortion posters caused for expectant parents in their failure to account for the complex human stories behind any pregnancy: 'Life doesn't fit neatly on posters. When you try to oversimplify it, you sometimes end up telling lies' (Fitzpatrick, 2018). Several complaints were made about the Save the 8th poster 'If Killing an Unborn Baby at Six Months Bothers You,' as the scenario it suggested — widespread late term abortion — was explicitly discounted by the proposed legislation (Department of Health, 2018; ní Aodha, 2018).

The problematic nature of this content was exacerbated by the overwhelming volume of referendum posters in public space and a frequent insensitivity in terms of their positioning. The display of posters outside schools was controversial, with parents complaining that this led to awkward and difficult conversations with their children (ní Aodha, 2018). The combative tactics of the Irish Council for BioEthical Reform (ICBR) proved particularly notorious. Despite their name, the ICBR are an international, largely North American group, without strong links to Irish anti-abortion campaigns, indeed the Irish No campaign felt the need to distance themselves from the group, with John McGuirk of the Save the 8th campaign telling the press:

These people are not Irish. They are not connected to our campaign, or to any other mainstream No campaign (Murray, 2018).

McGuirk's statement pointed to continuing sensitivities surrounding the funding of the Irish anti-abortion campaign and the perception that North American money was being used in an attempt to shape Irish social policy (Fox, 2018; Nagle, 2013), but also fitted with the campaign's framing of abortion as a 'foreign' (often British) imposition on Irish culture (Side, 2020: 107, 111-112). In the weeks leading up to the Irish referendum, the ICBR followed the tactics they had previously deployed in the United States and Canada, using banners and temporary displays of graphic foetal imagery as a form of protest, with a deliberate choice of locations (Williams, n. d.). In Ireland these locations were student campuses, iconic venues for the LGBTQI scene in Dublin, and maternity hospitals; in short, the group's positioning of their message seemed designed to cause offence rather than to persuade. The ICBR argued that their displays outside maternity hospitals would only cause distress to those who were 'ambivalent' about their pregnancies (Murray, 2018). The reductive cruelty of such statements was a striking reversal of the pro-choice campaign, with its focus on the complex, often painful, reproductive experiences of specific individuals. The combative tactics of the ICBR led to vibrant counter protests, for example, the group 'Radical Queers Resist' had an organised campaign to obscure the ICBR's messaging with various pride flagswhich here operated as oppositional banners as much as emblems of identity. The referendum campaign was also marked by less orchestrated instances of poster hacking: one Save the 8th poster, on Dorset St in Dublin, had its message altered from 'A License to Kill: Vote No' to, inevitably, 'A License to Kill: Vote OO7'; while the antiabortion announcements in the Stoneybatter area of inner-city Dublin were briefly 'enhanced' with coat-hangers. These local, small-scale interventions reached a wider audience through the uploading of photographs to social media.

The most extreme form of poster hacking was the illegal removal or destruction of posters, which both sides of the campaign suffered. These incidences occurred with such frequency that the Irish Council of Civil Liberties (ICCL) called for greater state protection for these 'important expression[s] of political speech' (Irish Council of Civil Liberties, 2018). The ICCL's valorising of the posters was not a majority view. Media debates, conducted during the referendum, largely argued for the control, regulation, limiting, or complete removal of political posters from public space, with one discussion on the state broadcaster RTÉ's current affairs programme, Claire Byrne Live, framing the posters as a type of visual litter (Claire Byrne Live, 2018). Such forms of censorship are an extreme solution with problematic consequences for the norms of democratic expression. In an interview the research group, Photography/Archives/Ireland, conducted with Rita Harold — an activist and organiser with the socialist pro-choice group, ROSA-Harold made the case for the political poster as an essential driver of Irish democracy, a means through which more marginal, less wealthy, political groups can present their message to the public.

Every referendum, every election campaign, many people say posters should be banned. Posters are banned in many places in the world and in those places there's really big parties, that run the country, and are corrupt, and it's really hard to challenge those parties, small forces can't get into the media, they can't engage in the air war because the air war is just the media, you're not allowed to put up posters, or 
it's billboards, extremely expensive billboards. Who had billboards in this recent referendum? The No side. The Yes side didn't have billboards. They are so expensive; you need to organise them way in advance. I think people would have been unhappy if posters had been banned in the referendum and we just had a load of No billboards all over the place (Loughnane, 2018).

Despite the offence and distress caused by the referendum posters - particularly the more graphic anti-abortion announcements featuring prenatal images - it seems that critique might be a more appropriate response than censorship.

Classic feminist critiques of foetal images, as we have seen, describe how their omissions and partial perspectives serve the narratives of anti-abortion groups, but these critiques often leave intact false assumptions about the innate coherence of photographic images. Such accounts cannot fully interrogate the belief which motivates the use of these visuals by many anti-abortion campaigns - the belief that foetal imagery has a fixed and clearly decipherable meaning which automatically conveys the humanity of the 'unborn.' We might return here to Enright's identification of the unsettling ambiguity of in utero images, which suggests that they are not so easily or immediately read. This illegibility is central to the lived experience of expectant parents, who are often reliant on medical staff for an accurate interpretation of their sonograms (Mitchell, 2001: 120-121; Taylor, 2008: 39). The slippage of ultrasound and other prenatal scans from medical functions to personal use also plays a part in their ambiguous and uncanny affects. Medical professionals often present these images as diagnostic tools, the initial first 'dating' scan, used to more accurately predict the due date, followed by an 'anomaly' scan to identify congenital conditions. But as Lisa Mitchell and Janelle Taylor's ethnographic studies of ultrasound clinics in North America have demonstrated, the prenatal scan is often marked by a contradictory mix between the diagnostic and the spectacular, with the expertise of sonographers falling somewhere between professional clinician and personal guide. As ultrasound has become more standard within obstetric medicine, a set of conventions have developed which combine its diagnostic role with the more nebulous functions of 'showing' the foetus to expectant parents, to provide reassurance, or, more contentiously, to assist with 'bonding.' ${ }^{6}$ Many ultrasound appointments are divided into an initial diagnostic section, where the sonographer or obstetrician focuses on taking measurements and checking for foetal abnormalities, and a more personal section where the sonographer decodes the image for expectant parents, pointing out key features and perhaps revealing the sex, or printing images as souvenirs (Mitchell, 2001; Taylor, 2008). The ultrasound as spectacle, complete with the provision of visual mementos, serves to objectify and commoditise the foetus, even while personalising it (Taylor, 2008: 135). While the diagnostic functions of ultrasound are a matter of concern and anxiety for expectant parents, they only form part of their use of prenatal images and the significance they attach to them (Watts, 2007: 232-233). The sonogram, despite its grainy indistinctness, and its humble materiality - generally small and printed on poor quality thermal paper-is prized as the first portrait of a future child. It often operates as an important accessory to public announcements of pregnancy and is sometimes preserved at the front of 'baby books,' souvenir albums designed to chart the early life of children. As Kelley Wilder points out, unlike other souvenirs, these images do not offer a nostalgic trace of experience but instead look forward; they are a memento 'that promises a future meeting' (Wilder and Von Zwehl, 2013: 132). This inherent futurity of sonograms also works against the imposition of immediate or definitive meanings. The emergence of 3D and 4D scans adds to this complexity; their increased legibility and detail has not been deemed diagnostically useful by the medical community but has led to a greater commodification of the foetal image, with many private companies using this technology to offer parents a pleasurable and reassuring experience, placing the foetus into a familial, rather than a clinical context (Roberts, 2012: 4). The visual clarity of these sonograms has been seen as offering a stronger sense of foetal personhood (Palmer, 2009), given this, it is surprising that these more recent medico-technological images were not widely used by the Irish anti-abortion campaign. The referendum posters illustrated here, for example, used older forms of visualisation — $2 \mathrm{D}$ ultrasound, in utero photographs strongly reminiscent of Nilsson's work, even a hand-painted foetal image on a pregnant belly.

We might also focus on the personal and social uses of in utero imaging to trouble the essential dichotomy between an intimate, somatic experience of pregnancy and a more distant, scientific and technological view of the foetus, suggested by some earlier feminist critiques. The discussion of prenatal imaging by the philosopher, Peter Paul Verbeek, is of interest here. Verbeek's approach is 'post-phenomenological' in that he refuses a model which considers relations between subjects and world through an unmediated intentionality; instead, he argues that the world we experience is always an interpreted reality, and our own subjectivity is always situated in some way. From this perspective, rather than seeing technology as offering 'second order and alienating ways to relate to reality,' we need to acknowledge that our experience of the contemporary world is technologically mediated (Verbeek, 2008:

\footnotetext{
${ }^{6}$ The conventions of ultrasound scans within obstetrics are of course cultural and change in different locations. But the practices in Canada and the United States, described by Mitchell and Taylor respectively, seem largely similar to those in Ireland.
} 


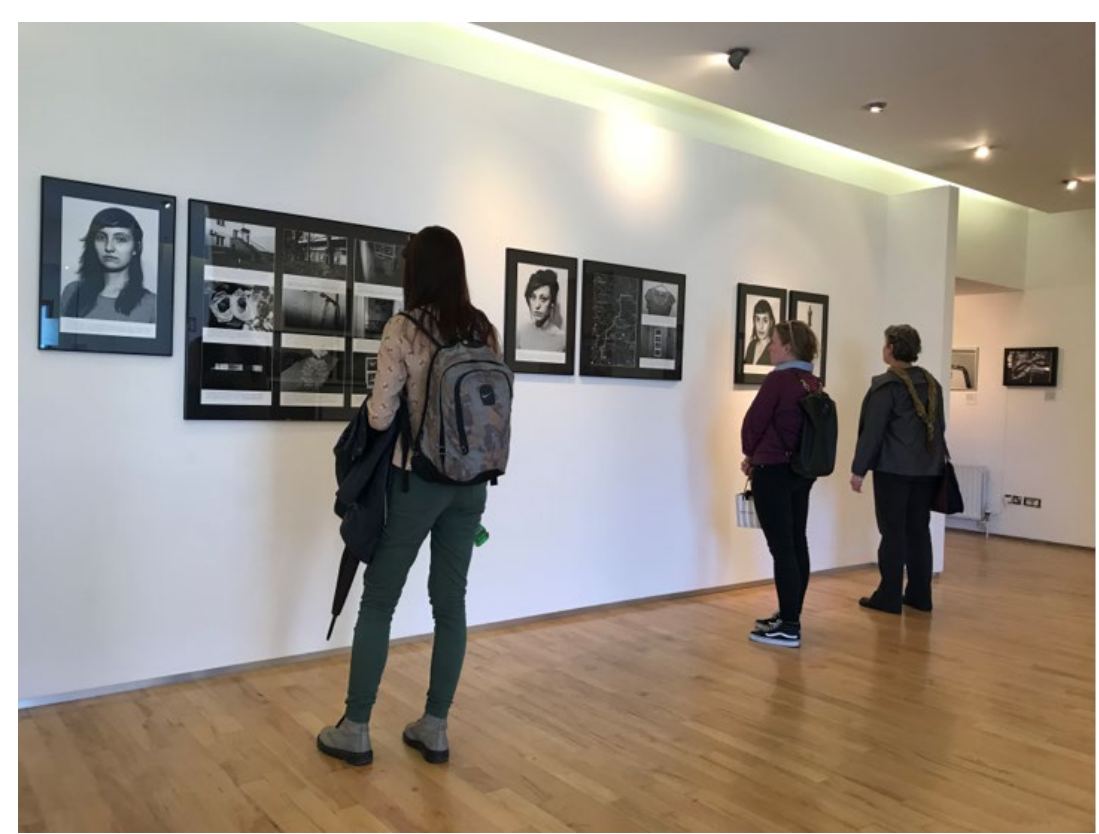

Figure 5. Installation view of Laia Abril 'On Abortion’, Copper House Gallery, Dublin, PhotoIreland Festival, 2018. Source: PhotoIreland. Used with permission

11). We cannot strip away technology and its role in forming our perceptions to arrive at 'original' phenomena; our practical engagements with the world, our interpretations of reality, even our moral decisions are already shaped by technology:

(...) moral intentions come about on the basis of technological mediations of the relations between humans and reality, and are always properties of human-technology associations rather than of prime movers (Verbeek, 2008: 14).

Verbeek considers obstetric ultrasound as an example of the necessary imbrication of humanity and technology. He argues against binary constructions which seek to place a dividing line between the person and the machine and advocate for greater human agency and control over technological images, an impossible task given how human perceptions of prenatal life are now so powerfully mediated by technical images such as sonograms. Verbeek acknowledges that: '(...) even though it might be a 'non-invasive' technology in a physical sense, ultrasound is far from non-invasive in a moral sense' and argues that these mediations produce a 'new ontological status of the foetus' (Verbeek, 2008: 14). This new status confers a type of personhood on the foetus-particularly evident in the gendering of the 'unborn' facilitated by ultrasound technology. Like earlier feminist commentators he highlights the ways in utero imaging separates the foetus from the body of the mother, which has a distancing effect, but he also notes that these technologies can bring the anticipated child closer to parents through the power of visualisation. Verbeek also examines how sonograms present the foetus as a possible patient-this renders expectant parents as 'decision makers' and ensures that our responses to these images are complex (Verbeek, 2008: 17). The parental choices opened up by prenatal scans and sonograms are far more ambivalent than anti-abortion campaigns acknowledge; this technology can also motivate the types of decisions that conservative reproductive politics would like to deny.

To further demonstrate the contingent meanings and effects of prenatal images, I want to finally discuss one very specific example. In the weeks leading up to the referendum vote, in May 2018, a sonogram was displayed which directly challenged the use of foetal imagery in the No posters on the streets; here, rather than acting as a spur for parental decision making, the prenatal scan serves to highlight the tragic consequences of a lack of choice (Figure 5). In contrast to the public visibility of the referendum posters, this image was accessible in the more contained space of the gallery, as part of PhotoIreland's timely exhibition of the work of the Spanish photographer, Laia Abril (PhotoIreland, 2018). The work shown by PhotoIreland was an edited sample from Abril's project, $A$ History of Misogyny Part 1: On Abortion, which was first exhibited in Arles as part of Les Recontres de la Photographie in 2016, and was recently shown as part of the exhibition, 'Reproductive: Health, Fertility, Aging,' at the Museum of Contemporary Photography, Chicago (Museum of Contemporary Photography, 2021; Recontres-Arles, n. d.). On Abortion forms the first chapter of Abril's long term visual research project, $A$ History of Misogyny, and also exists as a photobook, On Abortion and the Repercussions of Lack of Access, published by Dewi Lewis in 2018 (Abril, 2018; see also www.laiaabril.com). Abril's project frames abortion restrictions as a central expression of misogyny and demonstrates that the historical control of women's reproductive autonomy continues into the present, with 
repercussions that remain just as damaging and deadly in a contemporary world. Abril's approach traverses space as well as time, providing a global view of the often overlooked histories of the many thousands of women around the world who each year die, or are left with ongoing physical and psychological trauma, while undergoing illegal abortions or by being forced to continue or end pregnancies against their will.

Abril's exhibition in Dublin, as with other presentations of this work, combined images with text and audio/visual elements. The book too is very textual, reflexively includes research materials, and uses a variety of representational strategies. This allows a topic that has often resisted visualisation to be effectively imagined; the resulting work sits in a space between journalism and fine art and pushes against the conventions of documentary photography, indeed, might even be seen as a type of 'anti-photography.' In an interview with Sophia Griff, Abril argued:

(...) in a way my approach is completely against photography: I'm trying to visualise what you can't see. There are so many things that would be so much easier to photograph, things that don't elude visibility. But that's part of my relationship with the medium: wondering what we get to see and are able to react to. What do we not get to see, what do we prefer not to look at? The things that we don't want to seeor are not supposed to-are the ones that remain invisible in society. And they also remain invisible to the medium. I find it fascinating what an impact it can have on people when you visualise things that matter to them (Griff, 2020: 151).

Abril's work deploys still life, portraiture, archival images and staged reconstructions: her presentation of this diverse visual material demonstrates her extensive research on the topic; her awareness of how the imagery surrounding abortion has been weaponised; and a sensitivity to the ethical issues raised by her use of the intimate stories of individuals. The copyright page of the photobook contains a disclaimer stating that the project is a work of 'visual analysis and interpretation by the artist' and that some of the images are 'reconstructions or visual metaphors based on information discovered through extensive research' (Abril, 2018: n. p.). This disclaimer offers a necessary clarification-Abril's photographs may stretch definitions of documentary evidence, but they are nonetheless rooted in actual experience. The legitimacy conferred by direct, first-person narrative is also important here and the stories of those affected by reproductive politics are central to the work. Abril gathers these testimonies to form a devastating argument against the restriction of abortion, while still paying attention to the complexities of the specific circumstances faced by individuals in particular locations. This use of personal testimony as a form of public, political expression, combining the experiences of individual women to assert a universal demand, is a strategy that has frequently been deployed by pro-choice campaigns; many of these testimonies combine text with image, as in the pro-choice films discussed by Barbara Pickering (Pickering, 2003). But these political uses of text and image necessarily foreground an immediate legibility and a coherent linearity, constraints that Abril's work is free from, situated as it is in the context of fine art photography. Instead, both the various exhibitions of $O n$ Abortion, and the book, produce a complex layering of time and place, of factual evidence and personal testimony, of archival material and imaginative reconstructions. The narratives included in Abril's work range from mundane and routine accounts of abortion to the extreme and tragic cases that have often been considered more politically necessary and acceptable within pro-choice campaigns (Ludlow, 2008: 29).

The display of Abril's work, in Dublin, in the middle of the Irish referendum campaign, created a particularly charged viewing experience. Several of the personal histories included in Abril's project were of Irish people affected by the state's prohibition of abortion in almost all circumstances. These personal testimonies and Abril's visualising of them were placed alongside stories from diverse locations, such as Poland, Chile and Nicaragua, operating as a reminder that the Irish experience of strict reproductive control is far from exceptional. It is in this context that a sonogram was displayed; though not in a particularly prominent position it was located at the centre of the exhibition (Figure 5). This grainy ultrasound image is also placed towards the centre of the photobook, bookended by blank, black pages and printed over a double-spread on gloss paper; formatting that forces an attentive pause from the viewer/reader. In both exhibition and book a supplementary text is encountered either alongside or before the image, ensuring that this scan is always understood as a residue of gruelling personal circumstances, rather than as a generic image of prenatal life. The text reads:

MOTHER AT NINE YEARS OLD. In November 2015, nine-year old Inocencia gave birth to a baby boy in Nicaragua. He was the son of her own biological father, who had raped Inocencia repeatedly from the age of seven. Many countries, including Paraguay, Guatemala, Honduras, Venezuela, Somalia, Congo, Egypt, Iran, and Lebanon, do not consider rape a legitimate reason to abort and permit abortion only when the mother's life is at risk. Stricter still, Nicaragua, El Salvador, the Dominican Republic, Malta, and the Vatican are the five nations in the world where abortion is prohibited under any circumstance (Abril, 2018: n. p.). 
Abril gained access to this image through months of almost daily contact with a doctor involved with this case in Nicaragua, demonstrating the tenacity and care with which she gathered and produced the visual resources presented in On Abortion (Moroz, 2016). But for most viewers, the provenance of this contextualised image was no doubt of lesser importance than its emotional impact. Many of the viewers, who encountered the sonogram in the Copper House Gallery and read the supplementary text, would have been aware that Ireland could be placed among the list of countries where rape was not considered grounds for a termination of pregnancy. These viewers were also entering the gallery from streets festooned with prenatal imagery and must have been struck by this oppositional use of a prenatal scan. Abril's globalising caption, and my speculations about how the sonogram was experienced by Irish viewers, are open to the critique that they use abortion law to create equivalences between very different contexts and produce a new type of othering or designation of civility/incivility based on reproductive rights. However, this approach also posits a powerful, deeply felt, international activism surrounding abortion rights. In other ways, this sonogram challenged the North American and European accounts of ultrasound I have already considered and their focus on tensions between medical diagnostics and the production of a strange type of familial imagery (Mitchell, 2009; Taylor, 2008; Watts, 2007; Wilder and Von Zwehl, 2013). Here the sonogram operates as criminal, rather than medical evidence, and shows the family (and indeed the state) at its most abusive.

Abril's image could operate as a rebuke to the use of prenatal imagery on the anti-abortion referendum posters not simply because it transferred the sonogram from anti-abortion to pro-choice discourse; or because it changed the physical site of display from the public space of political propaganda, into the cultural space of the gallery; its oppositional charge was also because this ultrasound scan did not operate alone, but was instead placed alongside text and in conversation with many other images. The sonogram, in Abril's presentation of it, represented the forced pregnancy of a child victim of rape, Inocencia, but the lengthy caption that accompanied the image quickly moved from relating this tragic biography, to offering a factual listing of the many countries, outside Nicaragua, that discount rape as grounds for abortion; the emotiveness of Inocencia's story is thus balanced by legal fact. None of the personal narratives gathered by Abril are presented alone, but instead operate in concert with each other; on the walls of the gallery, or on the pages of the book, viewers move from text to image and from image to text and from one story to another. Other types of representation punctuate these narratives: still lives of the instruments used in reproductive health and of the objects used in desperate attempts to end pregnancies; the recorded confession of a Catholic woman seeking forgiveness for her abortion; and the blurred, indistinct portraits of those who can no longer consent to their own representation or tell their own stories. Abril gathers this evidence piece by piece in a manner that counterbalances the emotive personal histories from which this documentary material is drawn. In this way, although Abril's On Abortion is both affective and polemical, it avoids the emotional truthiness of the foetal personhood deployed in anti-abortion propaganda 7 . On the Irish referendum posters, prenatal imagery and text operated in concert to amplify a sentimental message, rather than to manage, contain or supplement emotion with factual information.

The use of prenatal imagery in anti-abortion politics may be simplistic and reductive, but it is also very affective. This visual culture offers an early example of a discourse that operates through emotion rather than reason, and it is not surprising that campaigns against abortion brought Christianity and right-wing politics together in a manner that now shapes a public discourse motivated by the expression of feeling and belief-rather than the presentation of logical, informed positions in search of consensus. Pro-choice groups have occasionally sought to identify and use an image that might carry the same emotional impact as the prenatal imagery deployed in anti-abortion messaging. Most often the images proposed are of women who died as a direct consequence of abortion restrictions, but this also involves the presentation of complex ethical questions as sentiment. Karen Sandlos argues that this marks a refusal of the particularity of individual experience to present instead a 'universalising claim.' The harnessing of death by both anti-abortion and pro-choice propaganda, these images of foetuses and martyred women, reduce complex situations to 'dichotomized and morally loaded questions of life versus murder, women versus fetuses, and right versus wrong' (Sandlos, 2000: 82). The use of a single image produces too simplistic and sentimental a view of reproductive politics. This propaganda also tries to reduce the multiple contexts, frames and meanings of any photographic image to an essential, transparent, and misleading singularity. The grainy $2 \mathrm{D}$ ultrasound scan encountered on an anti-abortion poster, at a hospital appointment, at the front of a baby book, or at the centre of Abril's On Abortion, are essentially the same image- there are few distinct visual markers that allow us to tell one sonogram from another-but our understanding of the sonogram dramatically changes according to the context in which it is encountered. Given these issues, it is unsurprising that the Together for Yes campaign retreated into text, but Abril's discussion of her work reminds us of the importance of visualising abortion, people need to have their experiences of reproductive control not just articulated but also seen; Abril's practice offers a

\footnotetext{
7 The term 'truthiness' was apparently first coined by the American television presenter, Stephen Colbert, in 2005. It has since entered standard dictionaries_-such as Oxford, Collins, and Merriam- Webster-defined as a quality of seeming or felt truth as opposed to actual truth (Zimmer, 2010).
}

(C) 2022 by Author/s 
salient example of how a pro-choice message can be visualised without being simplified. Three years after the Irish referendum, and its significant endorsement of pro-choice policy, the overwhelming presence of foetal imagery in public space seems distant. However, the Iona Institute's billboard campaign of 2019, and continuing anti-abortion protests outside maternity hospitals and clinics, suggest that finding strategies to counter the reductive visual culture of anti-abortion groups is just as urgent now, as it was in 2018. Tracing the history of in utero imaging; highlighting the ambivalences of prenatal scans and the multiplicity of meaning that arises from different situations of encounter; and placing these images in conversation with other images and text; provides the necessary complexity for an effective, oppositional view into the pregnant womb.

\section{REFERENCES}

Abril, L. (2018). On abortion and the repercussions of lack of access: A bistory of misogyny chapter one. Stockport: Dewi Lewis Publishing. See also: https://www.laiaabril.com/project/on-abortion/ (Accessed 15 March 2021).

Barthes, R. (1986). Camera lucida: Reflections on photography. New York: Hill and Wang.

Batchen, G. (2004). Forget me not: Photography and remembrance. New York: Princeton Architectural Press.

Berlant, L. (1994). America, 'fat', the fetus. Boundary 2, 21(3), 145-195. https://doi.org/10.2307/303603

Cadava, E. and Nouzeilles G. (eds). (2013). The itinerant languages of photography. New Haven and London: Yale University Press.

Claire Byrne Live. (2018). Radio Telefis Éireann (RTÉ), 23 April 2018.

Cosgrove, B. (2013). 'Drama of life before birth': Lennart Nilsson's landmark 1965 photo essay. Time, 4 March 2013. Available at: https://time.com/3876085/drama-of-life-before-birth-landmark-work-five-decades-later/ (Accessed 14 March 2021).

Curran, A. (2018). Interview with Sinéad Kennedy of the executive committee of Together for Yes. Photography/Archives/Ireland, 29 August 2018.

Department of Environment, Climate and Communications. (2019). Election poster information. Government of Ireland. Available at: https://www.gov.ie/en/publication/63f93-election-posters-information/ (Accessed 10 March 2021).

Department of Health. (2018). General scheme of a bill to regulate termination of pregnancy. Government of Ireland. Available at: https://www.gov.ie/en/publication/f501db-general-scheme-of-a-bill-to-regulate-termination-ofpregnancy/ (Accessed 10 March 2021).

Duden, B. (1993). Disembodying women: Perspectives of pregnancy and the unborn. Cambridge MA: Harvard University Press.

Duffy, M. (2015). Vote no. 1. Vienna: Anzenberger Edition.

Enright, A. (2018). Personal stories are precious things and they made all the difference-opinion piece. The Irish Times, 28 May 2018. Available at: https://www.irishtimes.com/opinion/anne-enright-personal-stories-areprecious-things-and-they-made-the-difference-1.3510189 (Accessed 14 March 2021).

Facebook Ireland. (2018). Statement 8 May. Available at: https://www.facebook.com/notes/facebookdublin/facebook-will-not-be-accepting-referendum-related-ads-from-advertisers-basedout/10156398786998011/ (Accessed 10 March 2021).

Field, L. (2018). The abortion referendum of 2018 and a timeline of abortion politics in Ireland to date. Irish Political Studies, 1-21. https://doi.org/10.1080/07907184.2018.1500461

Fitzpatrick, C. (2018). Anti-abortion posters fail to take account of life-opinion piece. The Irish Times, 23 April 2018. Available at: https://www.irishtimes.com/opinion/anti-abortion-posters-fail-to-take-account-of-life1.3470187 (Accessed 14 March 2021).

Fox, K. (2018). The young Americans trying to stop Ireland from voting yes to abortion-article. CNN, 23 May 2018. Available at: https://edition.cnn.com/2018/05/23/europe/ireland-abortion-referendum-americancampaigners-intl/index.html (Accessed 30 July 2021).

Griff, S. (2020). Beneath the surface: Laia Abril in conversation with Sophia Griff, in K. Fromm, S. Griff, M. Radtki and A. Stammler (eds), Image/con/text: Documentaische praktiken zwisehen journalismus, kunst und aktivisimus [Documentary practices between journalism, art and activism] (pp. 150-161). Berlin: Reimer Verlag.

Guttmacher Institute. (2021). Requirements for ultrasound. Available at: https://www.guttmacher.org/statepolicy/explore/requirements-ultrasound (Accessed 15 March 2021).

Iona Institute. (2019). New 'still one of us' billboard campaign launched-press release. 13 May 2019. Available at: https://ionainstitute.ie/new-still-one-of-us-billboard-campaign-launched/ (Accessed 31 July 2021).

Irish Council of Civil Liberties. (2018). ICCL calls on Government to defend freedom of speech and protect referendum posterspress release. 27 April 2018. Available at: https://www.iccl.ie/news/refpostersfreedex/ (Accessed 15 March 2021). 
Jansen, C. (2019). Foetus 18 weeks: The greatest photograph of the 20 $20^{\text {th }}$ century? The Guardian, 18 November 2019. Available at: https://www.theguardian.com/artanddesign/2019/nov/18/foetus-images-lennart-nilssonphotojournalist (Accessed 14 March 2021).

Jülich, S. (2015). Lennart Nilsson's a cbild is born: The many lives of a pregnancy advice book. Culture Unbound: Journal of Current Cultural Research, 7, 627-648. https://doi.org/10.3384/cu.2000.1525.1573627

Lippard, L. (1995). The pink glass swan: Selected essays on feminist art. New York: The New Press.

Loughlin, E. (2018). Abortion will be won 60:40 says Minister; save the 8th begins ' 12 weeks' campaign-article, Irish Examiner, 16 April 2018. Available at: https://www.irishexaminer.com/news/arid-30837576.html (Accessed 14 March 2021).

Loughnane, F. (2018). Interview with Rita Harold of ROSA. Photography/Archives/Ireland, 16 August 2018.

Ludlow, J. (2008). The things we cannot say: Witnessing the trauma-tization of abortion in the United States. Women's Studies Quarterly 36(1, 2), 28-41. https:// doi.org/10.1353/wsq.0.0057

McGreevey, R. (2018). Together for yes campaign says it is on course to raise $€ 500,000$-article. The Irish Times, 9 April 2018. Available at: https://www.irishtimes.com/news/ireland/irish-news/together-for-yes-campaignsays-it-is-on-course-to-raise-500-000-1.3455596 (Accessed 14 March 2021).

Metz, C. (1985). Photography and fetish. October, 34, 81-90. https://doi.org/10.2307/778490

Mitchell, L. M. (2001). Baby's first picture: Ultrasound and the politics of fetal subjects. Toronto, Buffalo and London: University of Toronto Press. https://doi.org/10.3138/9781442671140

Moroz, S. (2016). The photographer who captures the reality of abortion restrictions. The Cut, 8 July 2016. Available at: https://www.thecut.com/2016/07/artist-who-captures-the-reality-of-abortion.html (Accessed 15 March 2021).

Morse, F. (2012). 'Abortion tears life apart' adverts spark anger in Dublin-article. Huffington Post, 18 June 2012. Available at: https://www.huffingtonpost.co.uk/2012/06/18/anti-abortion-adverts-posters-billboardsireland_n_1605316.html (Accessed 30 July 2021).

Murray, S. (2018). 'We have asked them to stop': Both sides in referendum campaign condemn graphic posters outside maternity hospitals. The Journal.ie, 1 May 2018. Available at: https://www.thejournal.ie/icbr-graphicimagery-3988089-May2018/ (Accessed 14 March 2021).

Museum of Contemporary Photography, Chicago. (2021). Reproductive: Health, fertility, aging, Jan 19-May 23, 2021. Available at: https://www.mocp.org/exhibitions/2020/10/reproductive-health,-fertility,-agency.php (Accessed 15 March 2021).

Nagle, A. (2013). Why American pro-life dollars are pouring into Ireland. The Atlantic, 9 January 2013. Available at: https://www.theatlantic.com/sexes/archive/2013/01/why-american-pro-life-dollars-are-pouring-into-ireland /266981/ (Accessed 30 July 2021).

ní Aodha, G. (2018). More than 150 complaints about 'graphic' and 'false' referendum posters sent to Dublin City Council-article. The Journalie, 2 June 2018. Available at: https://www.thejournal.ie/poster-complaints-dublincity-4043897-Jun2018/ (Accessed 14 March 2021).

Palmer, J. (2009). Seeing and knowing: Ultrasound images in the contemporary abortion debate. Feminist Theory, 10(2), 173-189. https://doi.org/10.1177/1464700109104923

Panzer, M. (2020). 'A remarkable package of photographs for [a] dime': How life became life, in K. A. Bussard and K. Gresh (eds), Life magazine and the power of photography (pp. 46-61). New Haven: Princeton University Art Museum and Yale University Press.

Petchesky, R. P. (1997). Fetal images: The power of visual culture in the politics of reproduction, in R. N. Lancaster and M. di Leonardo (eds), The gender/sexuality reader: Culture, history, political economy (pp. 263-291). New York and London: Routledge.

PhotoIreland. (2018). PhotoIreland festival 2018, 1-31 May 2018. Available at: http://festival.photoireland.org/ year-2018/ (Accessed 15 March 2021).

Pickering, B. (2003). Women's voices as evidence: Personal testimony in pro-choice films. Argumentation and Advocacy, 40, 1-22. https://doi.org/10.1080/00028533.2003.11821594

Recontres-Arles. (n. d.). Expositions 2016. Available at: https://www.rencontres-arles.com/fr/expositions/ details?e $=2016$ (Accessed 15 March 2021).

Roberts, R. (2012). The visualised foetus: A cultural and political analysis of ultrasound imagery. London and New York: Routledge.

Sandlos, K. (2000). Unifying forces: Rhetorical reflections on a pro-choice image, in S. Ahmed, J. Kilby, C. Lury, M. McNeill and B. Skeggs (eds), Transformations: Thinking through feminism (pp. 77-92). London and New York: Routledge.

Side, K. (2020). Visual realignment? The shifting terrains of anti-abortion strategies in the Republic of Ireland, in R. A. Johnston Hurst (ed), Representing abortion (pp. 104-118). London and New York: Routledge. https://doi.org/10.4324/9781003016595-9 
Stabile, C. (1992). Shooting the mother: Fetal photography and the politics of disappearance. Camera Obscura, 28, 178-205. https://doi.org/10.1215/02705346-10-1_28-178

Stormer, N. (2008). Looking in wonder: Prenatal sublimity and the commonplace 'life'. Signs, 33(3), 647-673. https://doi.org/10.1086/523816

Taylor, J. S. (2008). The public life of the fetal sonogram: Technology, consumption and the politics of reproduction. New Brunswick, New Jersey and London: Rutgers University Press.

Verbeek, P. P. (2008). Obstetric ultrasound and the technological mediation of morality: A post-phenomenological analysis. Human Studies, 31(1), 11-26. https:// doi.org/10.1007/s10746-007-9079-0

Waterson, J. (2018). Google bans Irish abortion referendum adverts-article. The Guardian, 9 May 2018. Available at: https://www.theguardian.com/world/2018/may/09/google-bans-irish-abortion-referendumadverts (Accessed 14 March 2021).

Watts, G. (2007). One for the album. BMJ: British Medical Journal, 34(7587), 232-233. https://doi.org/10.1136/ bmj.39106.494931.94

Wilder, K. and Von Zwehl, B. (2013). A secret within a secret: Affect, identity and the fetal ultrasound, in B. Burbridge and C. Davies (eds), Photoworks annual: Issue 20 family politics (pp. 128-133). Brighton: Photoworks.

Williams, C. and Gill, D. (n. d.). Campus campaigns against reproductive autonomy: The Canadian Centre for Bioethical Reform Campus Genocide Awareness Project as propaganda for fetal rights. Active History. Available at: http:/ /activehistory.ca/papers/paper-18/ (Accessed 15 March 2021).

Zimmer, B. (2010). On language: Truthiness-article. The New York Times Magarine,13 October 2010. Available at: https://www.nytimes.com/2010/10/17/magazine/17FOB-onlanguage-t.html (Accessed 28 July 2021).

Citation: Loughnane, F. (2022). Foetal Images on Political Posters: Bodily Intimacy, Public Display and the Mutability of Photographic Meaning. Feminist Encounters: A Journal of Critical Studies in Culture and Politics, 6(1), 09. https://doi.org/10.20897/femenc/11753

Copyright (C) 2022 by Author/s and Licensed by Lectito BV, Netherlands. This is an open access article distributed under the Creative Commons Attribution License which permits unrestricted use, distribution, and reproduction in any medium, provided the original work is properly cited. 